\title{
LOADS ON WIND TURBINES ACCESS PLATFORMS WITH GRATINGS
}

\author{
Thomas Lykke Andersen ${ }^{1}$, Peter Frigaard ${ }^{1}$, Michael R. Rasmussen ${ }^{1}$ and Luca Martinelli ${ }^{2}$
}

\begin{abstract}
The present paper deals with loads on wind turbine access platforms. The many planned new wind turbine parks together with the observed damages on platforms in several existing parks make the topic very important. The paper gives an overview of recently developed design formulae for different types of entrance platforms. Moreover, the paper present new results on loads on grates based on both drag coefficient measurements and preliminary results on slamming from large scale tests. As expected both investigations show that platforms with grates give a significant reduction in the loads compared to closed plate platforms. The grate multiplication factor, defined as the peak load on the grate platform relative to the peak load on a closed plate platform was found approximately equal to the solidity of the grate.
\end{abstract}

Keywords: offshore wind; run-up; slamming; entrance platforms; grates; large scale tests

\section{INTRODUCTION}

Offshore wind turbine parks have up to now been placed in areas with relatively shallow waters where there is a high risk of wave slamming caused by waves with steep front or breaking waves. It has been observed in several parks that such slamming events might result in very high run-ups, i.e. in the order of $25 \mathrm{~m}$. Entrance platforms needed for safe access to the wind turbine have in several cases been damaged due to such run-up events during storms. The very significant impact loads cannot be prevented as the platforms for practical and safety reasons cannot be positioned high enough. As a consequence very strong structures are needed in order to prevent damage.

If wind turbines are placed in an area with risk of sea ice, a cone is typically applied to break the ice. The cone also provides a platform with access to the wind turbine. In case there is no risk of sea ice, a platform consisting of solid plates or gratings has typically been applied. Such platforms using gratings have been used on the large wind turbine park Horns Reef 1 in Denmark. This park is an example of a park with damaged platforms and grates that have been dislodged. Horns Reef 1 was one of the first bigger offshore parks and was thus designed before the run-up generated loads were well known. An example of a run-event at Hors Reef 1 is shown in Fig. 1 for a significant wave height approximately half of the design condition.
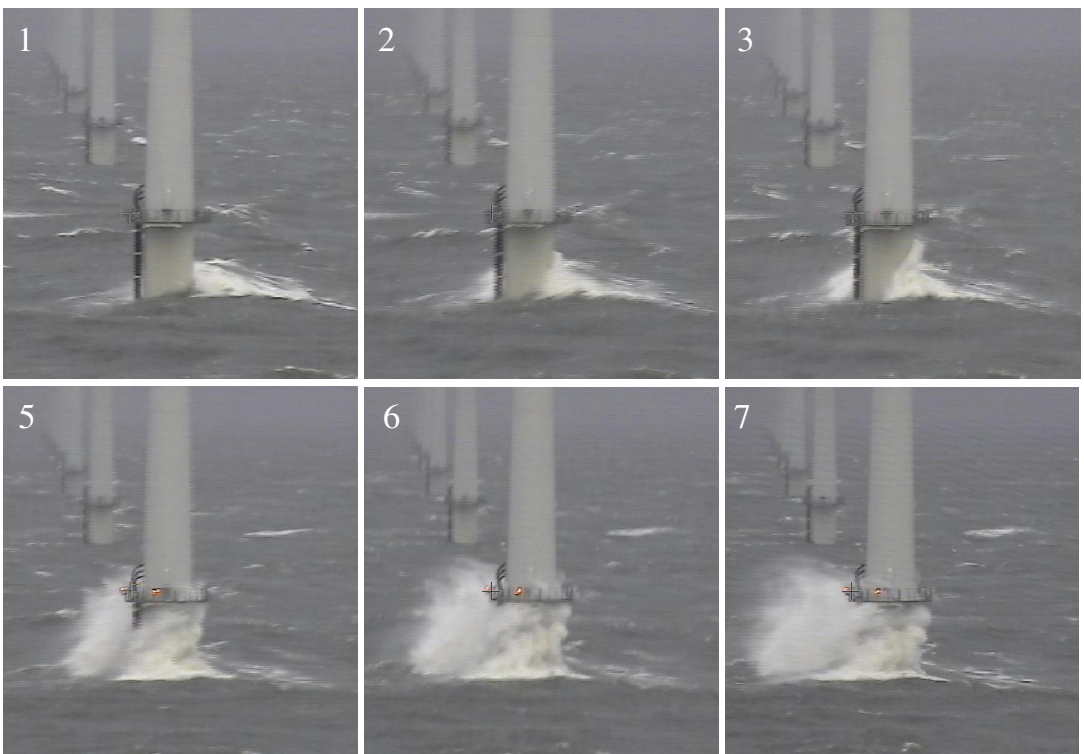

Figure 1. Example of observed run-up at Horns Reef 1, Denmark for $\boldsymbol{H}_{\mathrm{s}} \approx \mathbf{2 . 5} \mathrm{m}$, while the platform level is 9.0 $\mathrm{m}$ above SWL. $H_{\mathrm{s}, \text { design, } 50 \mathrm{y}}=5.3 \mathrm{~m}$.

\footnotetext{
${ }^{1}$ Dept. of Civil Engineering, Aalborg University, Sohngaardsholmsvej 57, DK-9000 Aalborg, Denmark

2 DISTART-Idraulica, University of Bologna, V.le Risorgimento, 2, Bologna, 40136, Italy
}
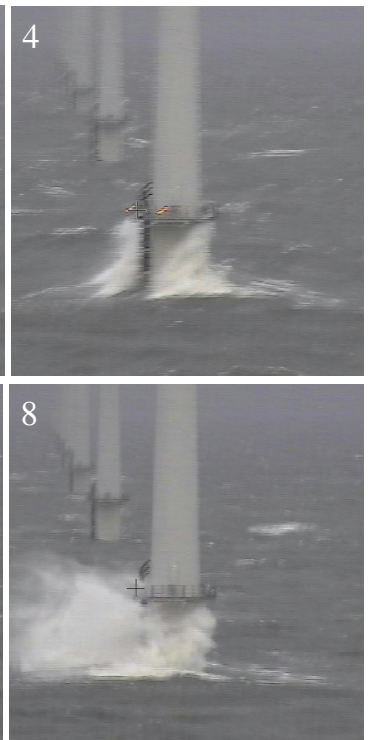
As part of the Horns Reef 1 repair project and for the design of Horns Reef 2, Aalborg University performed model tests. First model test investigations were presented together with a run-up formula by De Vos et al. (2007). A more detailed parametric model test investigation on run-up together with an updated run-up calculation method based on stream function wave theory is presented in Lykke Andersen and Frigaard (2006) and Lykke Andersen et al. (2010). Run-up has been modeled in a CFD model by Nielsen et al. (2008) and others.

Lykke Andersen and Brorsen $(2006,2007)$ presented and calibrated, based on small scale model tests, a calculation model for horizontal and conical closed plate platforms.

For platforms with grates the loads are reduced as found by Lykke Andersen and Rasmussen (2008) for drag and perpendicular attack. For slamming loads large scale or prototype measurements are needed in order to determine grate multiplication factors. The grate multiplication factor is here defined as the peak load on the grate divided by the peak load on the solid plate for identical impacts.

Based on above mentioned experimental results it was chosen to use conical platforms at Horns Reef 2. Fig. 2 shows a run-up event at Horns Reef 2 for a sea state with a significant wave height approximately half of the design value.

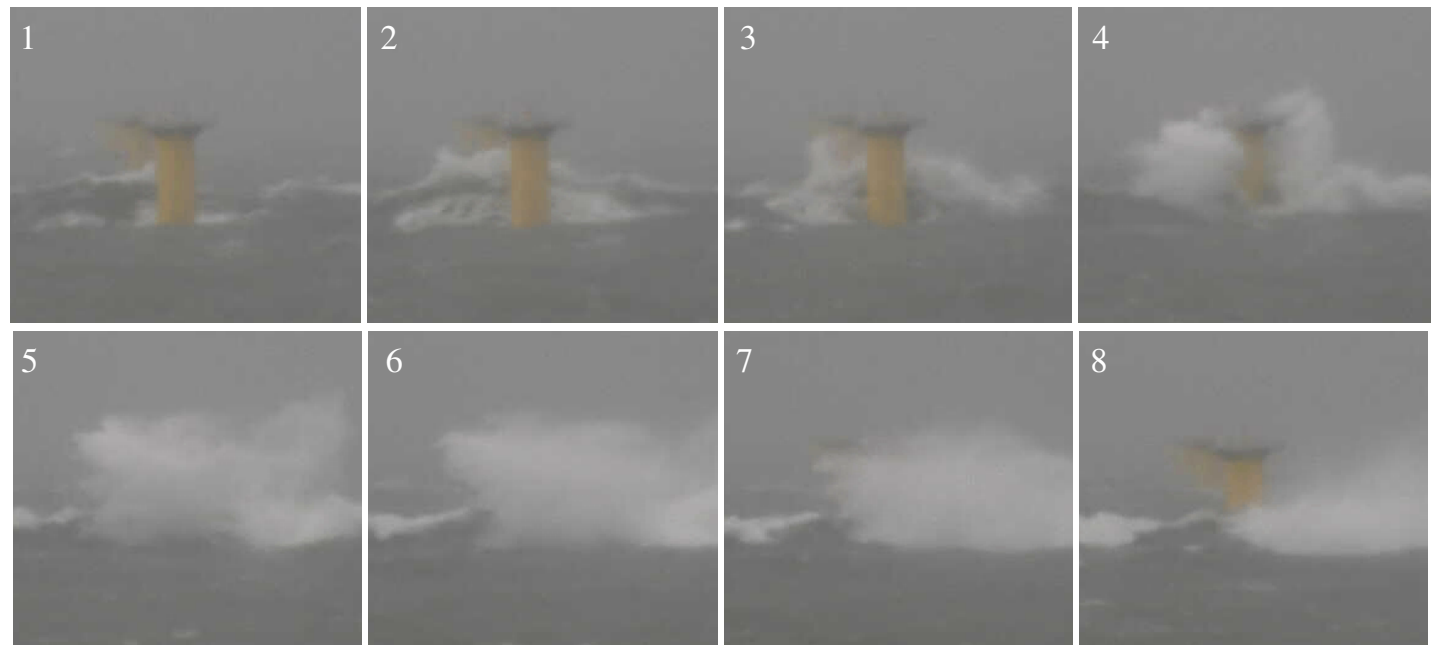

Figure 2. Example of observed run-up at Horns Reef 2, Denmark for $H_{\mathrm{s}} \approx 3.5 \mathrm{~m}$. Design wave height $H_{\mathrm{s}, \text { design }, 50 \mathrm{y}}=6.5 \mathrm{~m}$.

\section{AIM OF PRESENT PAPER}

The aim of the present paper is firstly to give an overview of design methods for loads on wind turbine entrance platforms established from above mentioned experimental studies. Secondly to present new results for loads on grates subjected to impacting stationary jets including oblique attack. Thirdly to present new preliminary results on grate multiplication factors from newly performed large scale tests in the Großen Wellenkanal (GWK), Hannover, Germany.

\section{EXISTING DESIGN FORMULAE FOR ENTRANCE PLATFORMS}

The existing design formulae is based on model tests carried out at Aalborg University and reported in Lykke Andersen and Frigaard (2006), Lykke Andersen and Brorsen (2006 and 2007). Based on above experiments the design formulae given in Eq. 1-3 is presented by Lykke Andersen et al. (2010) for run-up height (vertical distance from SWL ) in the absence of a platform.

$$
\begin{gathered}
R_{u, 2 \%}=\eta_{\max , 2 \%}+1.4 \cdot m \cdot \frac{u_{2 \%}^{2}}{2 g} \\
R_{u, \text { max }}=\eta_{\max }+1.4 \cdot m \cdot \frac{u_{\max }^{2}}{2 g}
\end{gathered}
$$

Here $R_{\mathrm{u}, 2 \%}$ is the run-up height exceeded by $2 \%$ of the waves and $R_{\mathrm{u}, \max }$ is the maximum run-up height. $g$ is the gravity acceleration and $m$ is the run-up factor that takes into account that the initial runup velocity is higher than the horizontal particle velocity in the crest. $\eta$ and $u$ is respectively the crest elevation and horizontal particle velocity in the crest calculated using stream function wave theory. In 
these calculations $T_{\mathrm{p}}$ is used as wave period and as wave height is used $H_{2 \%}$ and $H_{\max }$ for $R_{\mathrm{u}, 2 \%}$ and $R_{\mathrm{u}, \max }$, respectively. Based on small scale model tests Lykke Andersen (2010) found $m=4$ for $s_{0 \mathrm{p}}=0.02$ and $m=3$ for $s_{0 \mathrm{p}}=0.035$. The factor 1.4 is to take into account impacting waves not dealt with correctly by the measurement system used by Lykke Andersen in the small scale tests. It should be noted that even for waves that are not depth limited some waves are still breaking or close to breaking with a steep front and thus leading to high and thin run-ups. Therefore, it is recommended to apply the factor 1.4 in all typical applications of offshore wind turbines.

For estimation of the impact loads on platforms the run-up velocity $(v)$ at the platform level is used. This is calculated from the run-up height by assuming no energy loss in the run-up process from the platform level and upwards. This leads to the formula given in Eq. 3:

$$
v(z)=\sqrt{2 g \cdot\left(R_{u}-z\right)}
$$

where $z$ is the vertical distance from SWL to the platform. The slamming pressures $\left(p_{\max }\right)$ are calculated using the run-up velocity $(v(z))$ and a slamming load model as given by Eq. 4 .

$$
p_{\max }=\frac{1}{2} \rho v^{2} C_{s}
$$

Based on model tests the slamming coefficients were calibrated for the two different types of platforms. Slamming coefficients are given for the maximum peak load on the front part $\left(160^{\circ}\right.$ sector $)$ of the platform and for maximum local pressures over a prototype area of approx. $0.5 \mathrm{~m}^{2}$, cf. Lykke

\begin{tabular}{|c|c|c|}
\hline & $C_{\mathrm{S}, 160^{\circ} \text { sector }}$ & $C_{\mathrm{s}, \text { local pressure }}$ \\
\hline $\begin{array}{l}\text { Conical platform } \\
\text { Horizontal platform }\end{array}$ & $\begin{array}{l}1.2 \\
1.5\end{array}$ & $\begin{array}{c}6 \\
10\end{array}$ \\
\hline
\end{tabular}
Andersen and Brorsen (2007). The slamming coefficients are given in Table 1.

Eqs. 1-4 give the load model that exists for closed plate platforms. However, for porous platforms there exists no load model at the moment and it is thus the scope of the rest of this paper to present results for platforms with grates in order to provide a preliminary load model for platforms with grates.

\section{EXISTING DATA FOR LOADS ON GRATES}

The literature review on existing data on loads on porous structures is split into two parts, i.e. perpendicular attack and correction for oblique attack.

\section{Perpendicular Attack}

The normal force on a grate $\left(F_{\mathrm{x}}\right)$ from a stationary jet can be calculated from the momentum equation, eq. 5 .

$$
F_{x}=\rho Q \cdot\left(V_{x, \text { in }}-V_{x, \text { out }}\right)
$$

Here $Q$ is the flow and $V_{\mathrm{x}}$ is the velocity in the $\mathrm{x}$-direction (normal to the plate). For a non-porous plate the outflow will be parallel to the plate. For perpendicular attack we thus have $V_{\mathrm{x} \text {,in }}=V$ and $V_{\mathrm{x} \text {,out }}$ $=0$ and get $F_{\mathrm{x}}=\rho Q V=\rho V^{2} A$, i.e. corresponding to $C_{\mathrm{D}}=2$ for the plate. The maximum local pressure is the stagnation pressure corresponding to $C_{\mathrm{P}}=1$. The reason for $C_{\mathrm{D}}=2$ on the total force is that the exposed area is larger than the area of the jet. For a grate $V_{\mathrm{x}, \mathrm{out}}>0$ and we thus get a reduction in the load compared to the solid plate, i.e. $C_{\mathrm{D}}<2$.

Richards and Robinson (1999) found that the load reduction on grates compared to solid plates mainly depends on the porosity $(\beta)$ defined as:

$$
\beta=\frac{A_{o}}{A_{1}}
$$

where $A_{\mathrm{o}}$ is the area open to flow and $A_{1}$ is the total area. The pressure drop $(\Delta p)$ across a porous structure depends of the resistance against the flow through it. The resistance is often characterized by a pressure loss coefficient $K$. 


$$
K=\frac{\Delta p}{\frac{1}{2} \rho V^{2}}
$$

where $V$ is a characteristic velocity. For structures with a high porosity we can assume that most of the flow approaching the porous structure will pass through it. Therefore, the drag coefficient $\left(C_{\mathrm{D}}\right)$ is approximately equal to the loss coefficient $(K)$, but only if the velocity is taken as the velocity in the incomming jet and the reference area is taken as the total area including the openings (area of jet). This is important as Richards \& Robinson (1999) and others give values of hydraulic loss coefficients $(K)$ for different types of porous elements that can be used as estimates for the drag coefficients. Richards \& Robinson (1999) gives values of $K$ for round wire mesh screens as function of porosity and Reynolds number. They also give the following formula for estimating the relationship between drag coefficients for a solid plate $\left(C_{\mathrm{D} \text {,solid }}\right)$ and for a round wire mesh screen $\left(C_{\mathrm{D}}\right)$ :

$$
\frac{C_{D}}{C_{D, \text { solid }}}=1-\beta_{e}
$$

The effective porosity $\beta_{\mathrm{e}}$ takes into account the influence of the geometry and the size of the openings. For instance grates made from elements with sharp edges are expected to observe larger forces than elements with rounded edges as observed for single body drag. $\beta_{\mathrm{e}}=\beta$ for round wire mesh screens while $\beta_{\mathrm{e}}=0.75 \cdot \beta$ for structures made from slats with a depth comparable to their width (Richards \& Robinson 1999). For structures made from flat webs the effective porosity may be about 2/3 of the geometric porosity (Morgan 1962).

Several other suggestions for the drag coefficient as a function of porosity have been suggested. Annand (1953) propose that the drag coefficient can be found as:

$$
C_{D}=\frac{a \cdot\left(1-\beta^{2}\right)}{\beta^{2}}
$$

where $a$ is a Reynolds number dependent coefficient. For high Reynolds numbers, this coefficient becomes constant with a value around 0.55 .

The loading on free standing porous walls is given by Richards and Robinson (1999):

$$
C_{D}=1.2 \cdot\left(1-\beta^{2}\right)
$$

For high porosities $(\beta>0.7)$ equations 8,9 and 10 give very similar results.

\section{Oblique Attack}

For solid plates the maximum force is achieved when the jet is perpendicular to the plate. This can be realized by the momentum transfer described by Eq. 5. By changing the angle of the jet, the force is split into a normal force due to pressure differences and a friction force parallel to the plate. The normal force can be found from Eq. 5:

$$
F=\rho Q \cdot(V \cdot \sin (\theta)-0)=\rho V^{2} A \sin (\theta)
$$

where $\theta$ is the angle between plate and jet and $A$ is the area of the jet (measured on a plane perpendicular to the flow direction).

For mesh type grates with round bars, the reduction is as for the plate and the drag coefficient can be founds as (Richards and Robinson 1999), (Idelchik 2003):

$$
C_{D}=C_{D, \text { normal }} \cdot \sin (\theta)
$$

This can be explained by the fact that the effect on the individual round bar is the same, independently of the angle. Therefore, the normal force to the mesh will follow the usual sine relation as found for the solid plate.

For grates with rectangular bars and a significant depth of the grate, only little literature is found on the influence of the angle of attack. The complication of this structure, compared to grates made from round bars, is that the depth of the grate is exposed to the water jet as the jet is angled. Due to little knowledge on the effect of thick grates, the present experiments will measure the normal force as a function of angle of attack. 
The assumption behind equation 11 is that the jet of water is smaller than the grate as investigated in the present tests. Therefore, it is assumed that the run-up tongue is smaller than the platform area with grates.

\section{GRATE MULTIPLICATION FACTORS BASED ON DRAG TESTS}

Set-Up

The set-up for the drag measurements consisted of a frame connected to a large force transducer, cf. Fig. 3. The different grates have been attached to this frame when tested. The force is measured for a jet generated by a nozzle connected to two large pumps. The connection of the two pumps to the nozzle is shown in Fig. 3. As the nozzle was placed within few centimetres from the plate/grate the diameter of the impacting jet is very close to the inner diameter of the nozzle equal to $0.081 \mathrm{~m}$. The pumps used are of type FLYGT 5.2kW and has a maximum flow rate around $35 \mathrm{l} / \mathrm{s}$ each. In the present tests one and two pumps have been used. The flow was measured by a clamp on ultrasonic flow transducer.
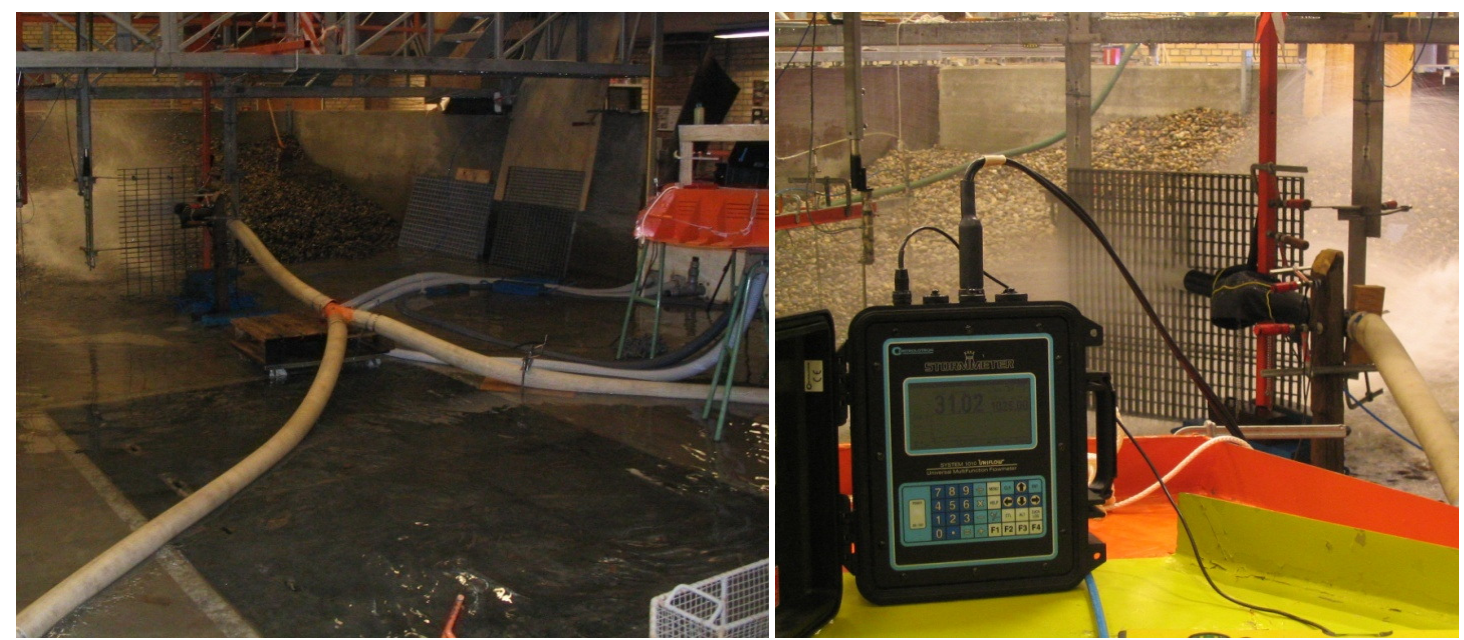

Figure 3. Photos of the set-up used for the drag tests.

The influence of entrained air has been studied in the tests. The air was added in the outer part of the nozzle approximately $20 \mathrm{~cm}$ from the outlet. To get a close to uniform air entrainment the air is added through a nozzle perforated in the side facing the outlet as shown in Fig. 4. The air flow was measured to approximately $5 \mathrm{l} / \mathrm{s}$, corresponding to $10 \%$ air in the tests performed with both pumps running at maximum power. The nozzle was also in place for the tests with no air. A comparison of the drag coefficient for the solid plate was performed for measurements with and without the air nozzle in place. From this it was concluded that the influence of the air nozzle itself was very small.

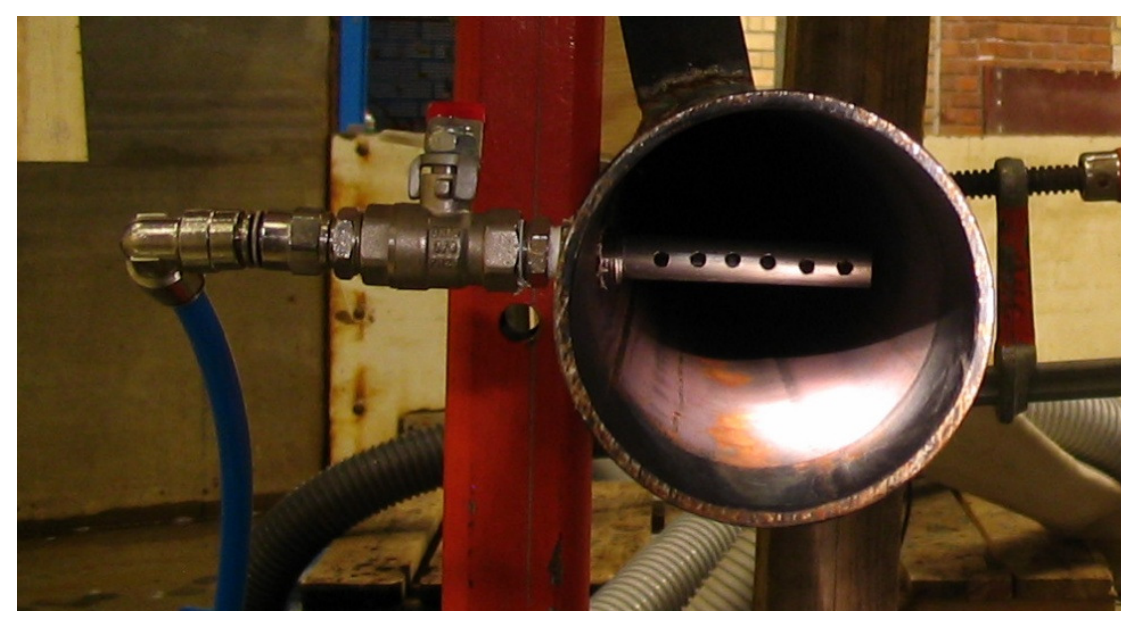

Figure 4. Picture of air nozzle. 
Four grates and a solid plate were tested. The dimensions of the different grates are given in Table 2. It can be seen that three of the grates have very similar porosity and only the Weland J9 has a porosity that is significant different from the others.

\begin{tabular}{|c|c|c|c|c|}
\hline & openings & bar thickness & bar height & Porosity $(\beta)$ \\
\hline Solid plate & - & - & - & 0.00 \\
\hline Fiberline 40 & $33.5 \times 33.5 \mathrm{~mm}$ & $6.5 \mathrm{~mm}$ & $30 \mathrm{~mm}$ & 0.70 \\
\hline Fiberline 50 & $42.5 \times 42.5 \mathrm{~mm}$ & $7.5 \mathrm{~mm}$ & $50 \mathrm{~mm}$ & 0.72 \\
\hline Weland H4 30/5 SAFETY & $43.0 \times 28.0 \mathrm{~mm}$ & $7.0 \& 5.5 \mathrm{~mm}$ & $30 \mathrm{~mm}$ & 0.72 \\
\hline Weland J9 30/3, non-galvanized & $92.0 \times 38.0 \mathrm{~mm}$ & $6.0 \& 3.0 \mathrm{~mm}$ & $30 \mathrm{~mm}$ & 0.87 \\
\hline
\end{tabular}

However, the structure of the Fiberline and Weland grates are very different, cf. Fig. 5, and this might influence the observed forces. The rounded bars used on the Weland grates generally give smaller resistance than bars with sharp edges used for the Fiberline grates.
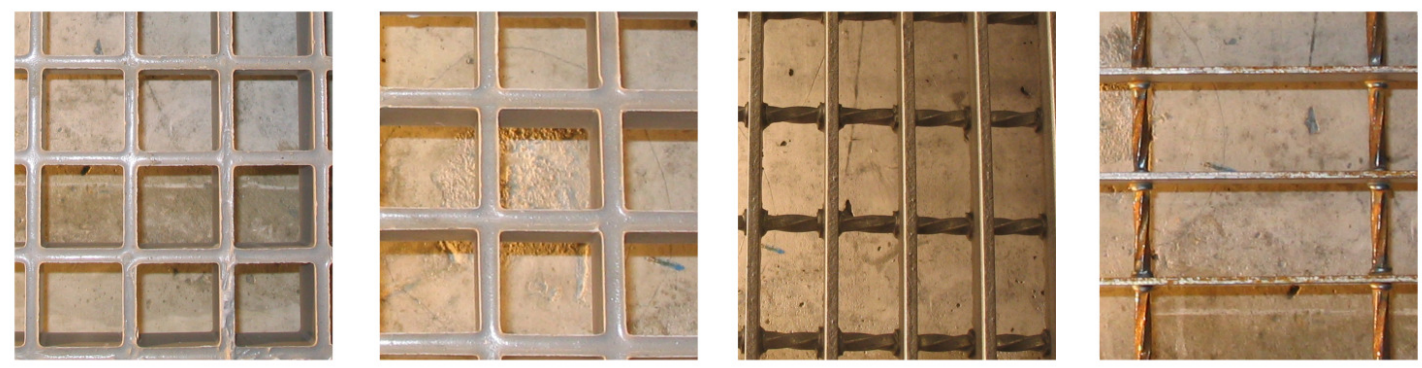

Figure 5. Pictures of the four grates tested. From left to right is Fiberline 40, Fiberline 50, Weland $\mathrm{H} 4$ and Weland J9. The pictures are taken so the grates are viewed from the bottom (the side facing the jet).

\section{Results Perpendicular Attack}

Fig. 6 shows the results for the solid plate. These results are included to verify the clamp-on ultrasonic flow transducer using the two different sets of electrodes available for the flow transducer. Moreover, a fitted curve to each of the electrode pairs is also included in the figure. These curves have been fitted with the assumption of a constant $C_{\mathrm{D}}$. It can be seen that there is only $10 \%$ difference in the two $C_{\mathrm{D}}$ values for the two different pairs of electrodes. This corresponds to only $3 \%$ differences in the two flow rates. Moreover, $C_{\mathrm{D}}=2$ as given by the momentum equation is validated by the tests.

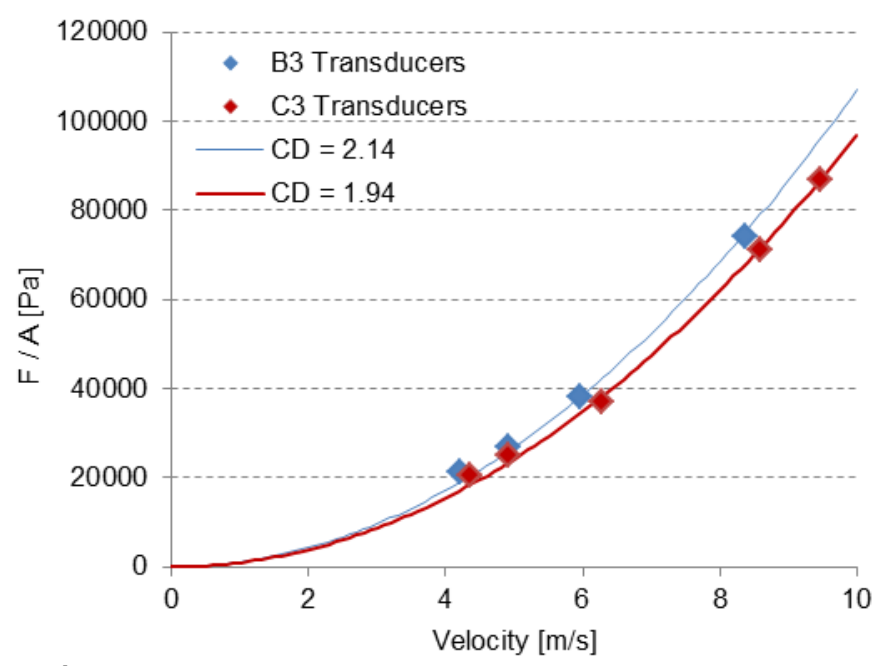

Figure 6. Solid plate results.

Pictures of the impact on the four different grates and the solid plate are shown in Fig. 7 for perpendicular attack and no air added. It can be seen that the area of the jet is quite small compared not only to the structure of the grates but also compared to prototype conditions. It is possible that this have some influence on the obtained results as the spreading on the rear side of the grate will probably be different if a larger area is exposed. Moreover, the relation between the force on the plate and on the grate might depend on the area considered and the size of the jet. Due to the large spreading on the rear 
side, no significant downstream suction is expected in the tests as it seems well ventilated. If the exposed area is significantly larger in prototype this might not be true for the prototype conditions. As a consequence the obtained results might for the grates be on the unsafe side. Moreover, the situation considered is drag and not slamming as in prototype. In order to investigate these two items large scale or prototype tests are needed.
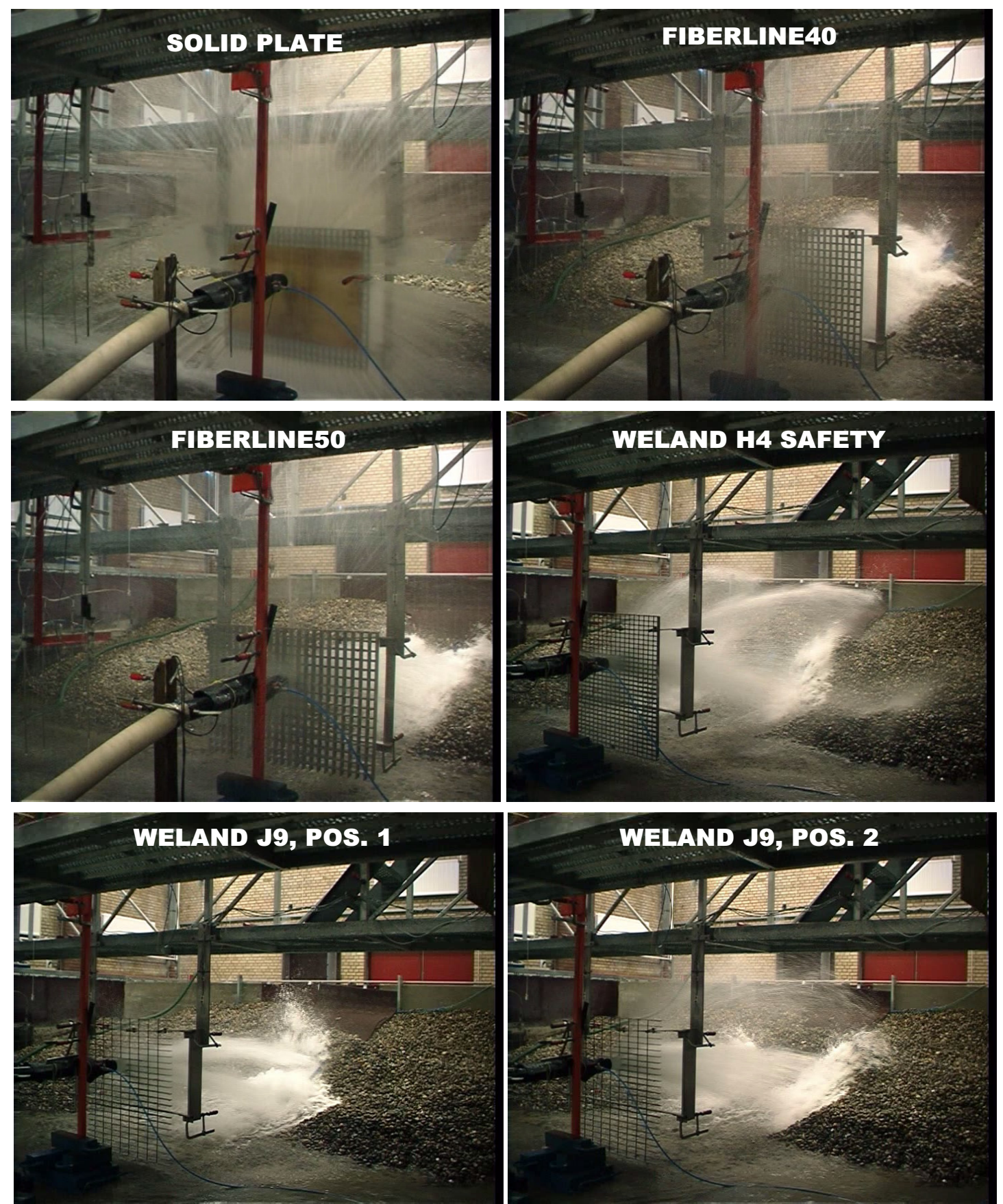

Figure 7. Pictures of perpendicular impact on the solid plate and the three different grates for close to identical jet velocities and no air added.

The large openings in the Weland J9 grate compared to the size of the impacting jet, makes the jet impact point very important. In the present study two positions have been considered for this grate, $\mathrm{cf}$. Fig. 10. Position 1 corresponds to maximum porosity $(\beta \approx 0.95)$, while Position 2 corresponds to minimum porosity $(\beta \approx 0.83$ ). Moreover, the pictures illustrate that for the grates most of the water flow through the grate and has great velocity also behind the grate. This indicates significant smaller forces on the grates compared to the solid plate. It can also be seen that the results for the Weland J9 grate is 
not as strong influenced by the jet impact point as the two porosities indicate, but anyway the influence is important.
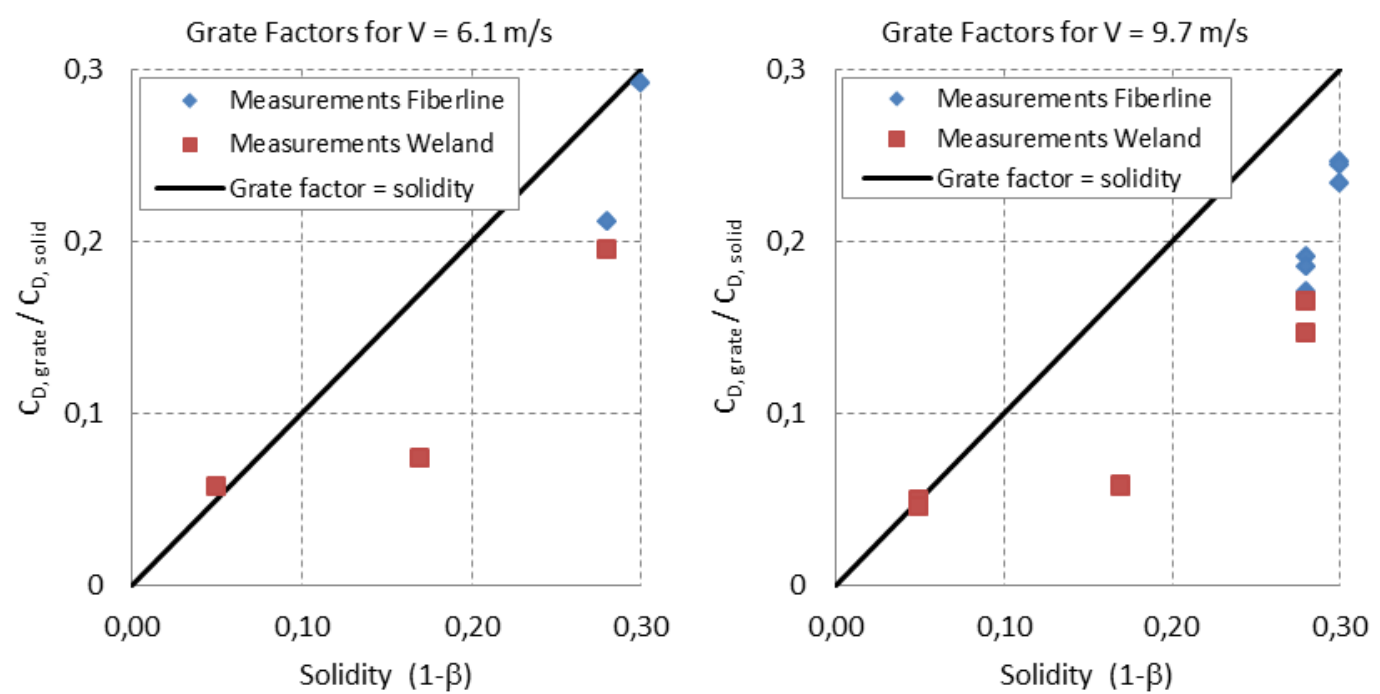

Figure 8. Measured drag coefficients for the different grates for perpendicular attack and no air added. The reference area used is the area of the jet.

Within the uncertainties related to these tests, it is clear from Fig. 8 that the grate multiplication factor is not strongly dependent on the Reynolds numbers. However, the tests with the larger flow rate (higher Reynolds number) give generally slightly smaller grate multiplication factors. The upper limit for the grate multiplication factor seems to be the solidity of the grate as also indicated by Eq. 8 .

The two Fiberline grates give drag coefficients that are higher than those for the Weland grates. This is expected mainly to be due to the rounded bars used for the Weland grates instead of the sharp edged slats used for the Fiberline grates. Grates with sharp edged elements correspond to a smaller effective porosity

However, in some cases the grate multiplication factors are smaller than expected. This can maybe be explained by the well ventilated rear side or the very large Reynolds numbers in the present tests. Another explanation could be that even for very porous grates the flow is much different in the present tests to the flow used in the resistance tests. In the present tests this was observed as some part of the water flows parallel with the grate and the rear side is well ventilated. Therefore, the flow is significant different from the resistance flow where the rear side is not ventilated and the water cannot escape parallel to the grate. The case in the prototype is expected to be something in between as the jet is much bigger than tested in the experiments but smaller than the platform.

\section{Influence of Oblique Attack and Air Content}

Fig. 9 presents all the results obtained for the different angles of attack and the two air flows tested. The results states that the forces on a solid plate will depend on the angle of attack as given in Eq. 11 . When no air is added $C_{\mathrm{D} \text {,normal }} \approx 2.0$ as given by the theory in Eq. 5 . When $10 \%$ to $16 \%$ air is added it still follows Eq. 10 but with $C_{\mathrm{D} \text {,normal }} \approx 2.6$. The increase in the drag coefficient when air is added was unexpected from a momentum point of view, but could be due to a non-uniform velocity and air distribution (model effects). Moreover, the 10\% drop in water flow from the pumps as reported by the flow transducer when $10 \%$ air is added could be wrong. An explanation could be that more water is thrown backwards from the plate when air is added. Even though it was visually observed that the air changed the flow pattern it is believed that the difference is mainly due to model effects. 

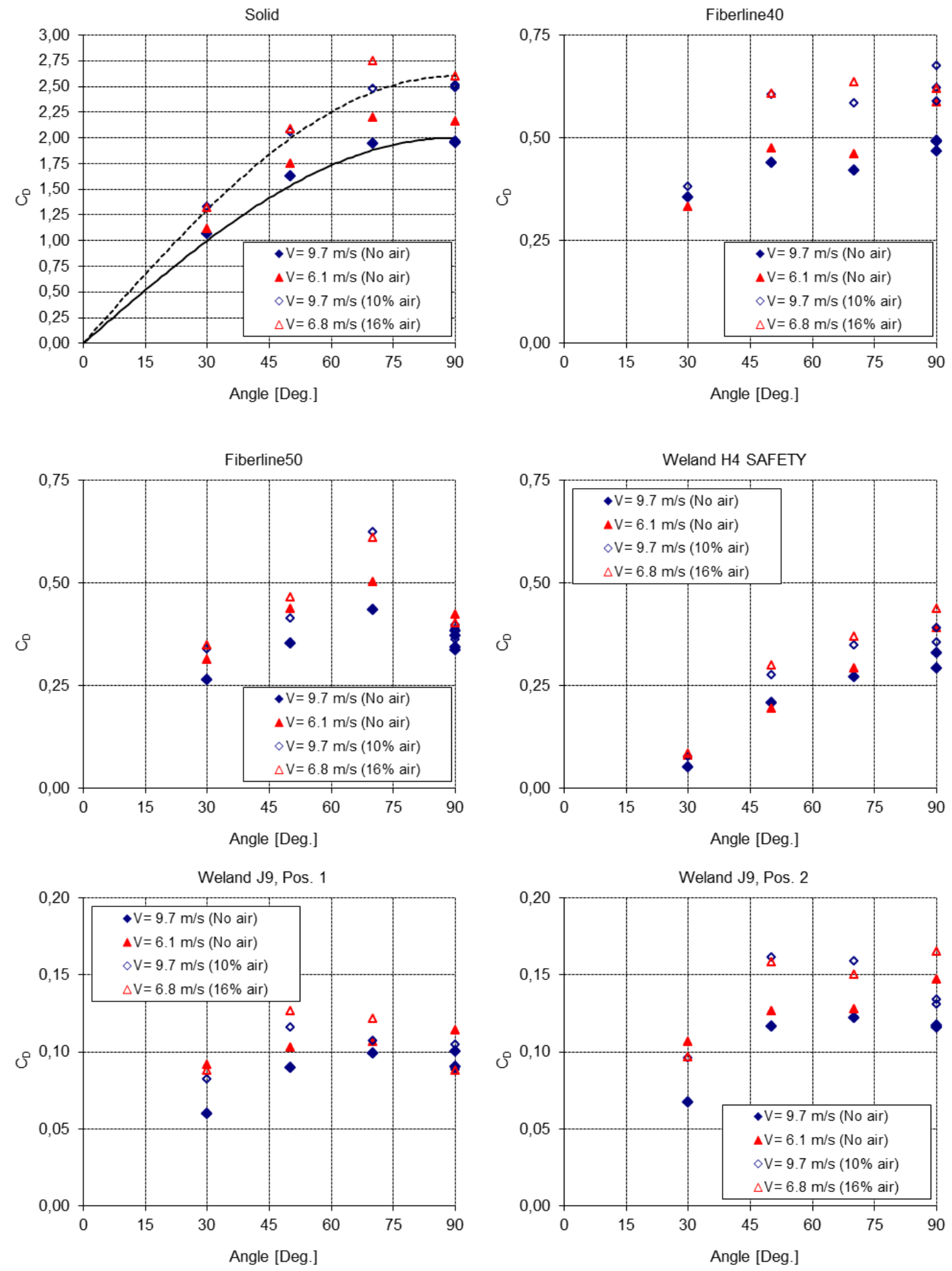

Figure 9. Measured forces at different angle of attack for the different grates. For the solid wall case two curves are given corresponding to Eq. 11 using $C_{\mathrm{D}}=2.0$ and $C_{\mathrm{D}}=2.6$ for perpendicular attack for no air added and air added, respectively.

The grate will observe approximately the same out of plane force for attack angles between 90 and 50 degrees, cf. Fig. 9. In case of very oblique attack the out of plane forces are decreasing. However, a special attention has to be given to the results for the Fiberline 50 grate as the measured forces are largest for a small obliqueness. The reason for this is expected to be that the Fiberline 50 grate is the thickest of the four grates tested. It should be noted that when the jet is angled in relation to the grate, the depth of the grate is exposed to the jet. This will increase the projected frontal area. At the same time, when the jet is angled in relation to the grate, only a part of the force will be directed 
perpendicular to the grate. The projected area will be directly proportional to the sine of the angle, while the projected forces will be the inverse proportional to the sine of the angle.

\section{LARGE SCALE TESTS}

The stationary drag tests have some open points regarding transformation to prototype conditions where a major difference is that the load on the grate in prototype is not drag but slamming dominated. The jet tested in the drag tests was very small leading to well ventilated rear side. Moreover, there seems to be a significant influence of the angle of attack leading to larger loads for slightly oblique attack for thick grates with flat bars. These three uncertainties make large scale tests very important in order to have a better estimation of the grate multiplication factor. The large scale tests presented here are some recently performed tests in the Großen Wellenkanal (GWK), Hannover, Germany and can be considered as scale 1:8 to 1:10 of typical offshore wind turbine parks.

\section{Test Set-Up}

A pile with a diameter of $0.56 \mathrm{~m}$ was installed $111 \mathrm{~m}$ from the generator. A sandy sea bed was used with a thickness varying from $0 \mathrm{~m}$ approximately $50 \mathrm{~m}$ from the generator to $1 \mathrm{~m}$ at the pile. 22 surface elevations gauges were installed to measure the wave transformation along the channel. The wave parameters given in the present paper are those measured at the pile.

Run-up without platforms installed was first measured using a high speed video camera. Afterwards the tests were repeated with load measurements on the platforms.

For the load measurements a solid plate platform and two grates with porosities $70 \%$ and $84 \%$ were tested at several platform levels. The outer diameter of the platforms were $1.00 \mathrm{~m}$ giving a platform width of $0.22 \mathrm{~m}$. Both grate types were made of steel slats. The platforms were mounted with a small gap to the pile in order to be able to measure the total load. The gap was in the range 1 to $10 \mathrm{~mm}$ on the front side and a larger gap on the rear side. The platform had three supports (120 degree interval) each connected to a force transducer. Fig. 10 shows the two front support force transducers (U9B from HBM, with nominal forces $10 \mathrm{kN}$ ). The third support and associated force transducer (U9B from HBM, with nominal force $2 \mathrm{kN}$ ) located on the rear side of the pile cannot be seen in the figure. Per force transducer, a knuckle eye is used (mounted between the transducer and the platform) as forceintroduction aid and to avoid bending moments. An analog lowpass filter was applied on the three force transducers with a cut-off frequency of $316 \mathrm{~Hz}$.

In addition to the force measurements were measured impact pressures on the closed plate platform by 25 pressure cells (DRUCK PDCR 830).

Sample frequency was $1000 \mathrm{~Hz}$ for tests with the two grate platforms. For the solid plat platform the sample frequency was increased to $4000 \mathrm{~Hz}$ to have better resolution on the impact pressures.
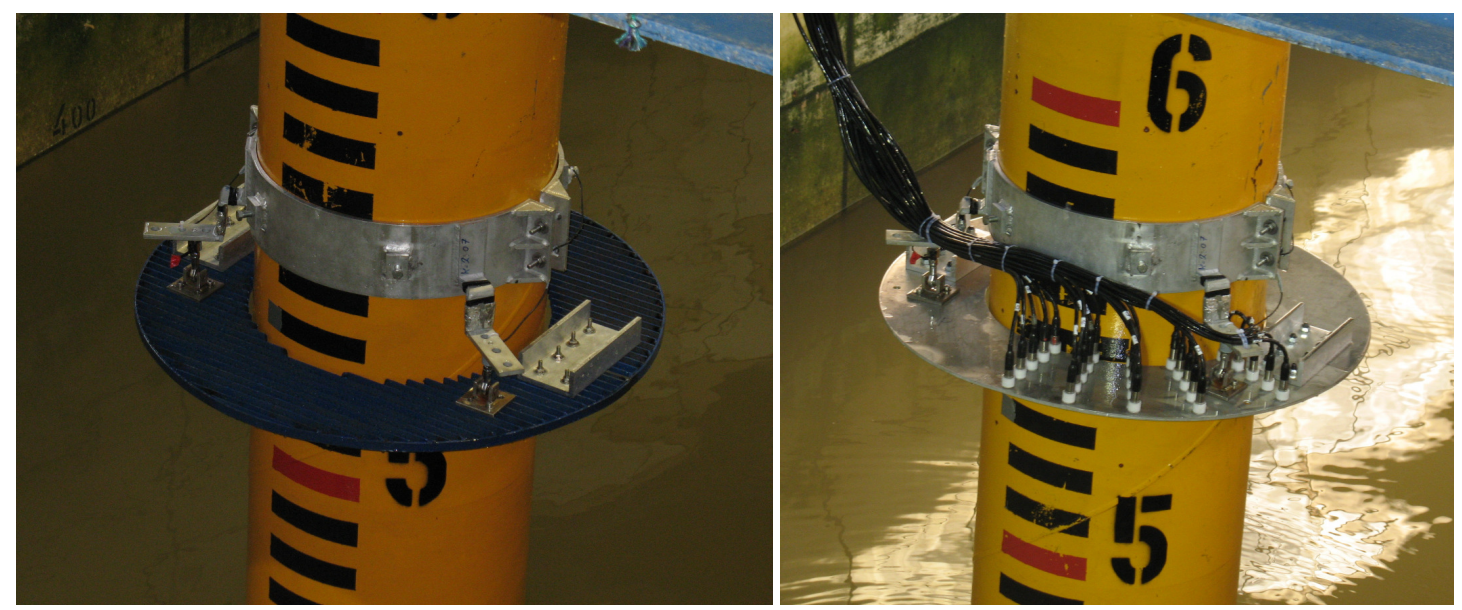

Figure 10. Photo of grate (70\% porosity) and solid platform installed.

\section{Test Programme and Analysis}

A number of different sea states were tested including freak waves and different irregular seas generated from the JONSWAP spectrum with $\gamma=3.3$ for water depths $(h)$ between 2 and $3 \mathrm{~m}$ at the pile. Each of the irregular sea states included approximately 500 waves. 
For the present paper only a preliminary analysis is presented as only the platform level $+1.75 \mathrm{~m}$ and the sea state given by the following sea state parameters at the pile $h=3.0, H_{\mathrm{m} 0}=1.0 \mathrm{~m}$ and $T_{\mathrm{p}}=$ $5.9 \mathrm{~s}$ is considered. This sea state has been repeated with identical steering signals for run-up measurement and load measurement on the three tested platform types. Thus interrelated run-up levels and loads have been obtained. For this sea state there are five run-up events giving approximately the same run-up height. The measured green water thick run-up reached approximately level $+1.8 \mathrm{~m}$ for these five events with spray up to at least level $+3.0 \mathrm{~m}$. The run-up formulae by Lykke Andersen et al. (2010), Eq. 2, based on small scale results give for the highest wave a run-up height of $3.3 \mathrm{~m}$ and is thus in quite good agreement with the spray measurements.

\section{Results}

Figs. 11-13 show a comparison of the event giving the maximum total force (sum of the forces in the three supports) on the three types of platforms. The largest impact on the three platform types occurs for different waves all giving a very large run-up. In the three events the individual wave height is more or less identical with $H_{\max } \approx 1.6 \mathrm{~m}$.

The slamming load model based on small scale results give for the closed plate platform a maximum vertical force of $1.0-2.2 \mathrm{kN}$, depending on the assumption of the pressure outside the 160 degree sector with pressure cells. $1.0 \mathrm{kN}$ is obtained if zero pressure is assumed outside the sector. 2.2 $\mathrm{kN}$ is obtained if the pressure outside the sector is assumed identical to pressure inside the sector. The most realistic estimate is believed to be close to the lower end of the interval.

A total load of $2.3 \mathrm{kN}$ was measured in large scale for the closed plate platform. Further analysis of run-up and loads on the closed plate platform for several tests is needed to analyze the deviations in predicted and measured loads for the closed plate platform.

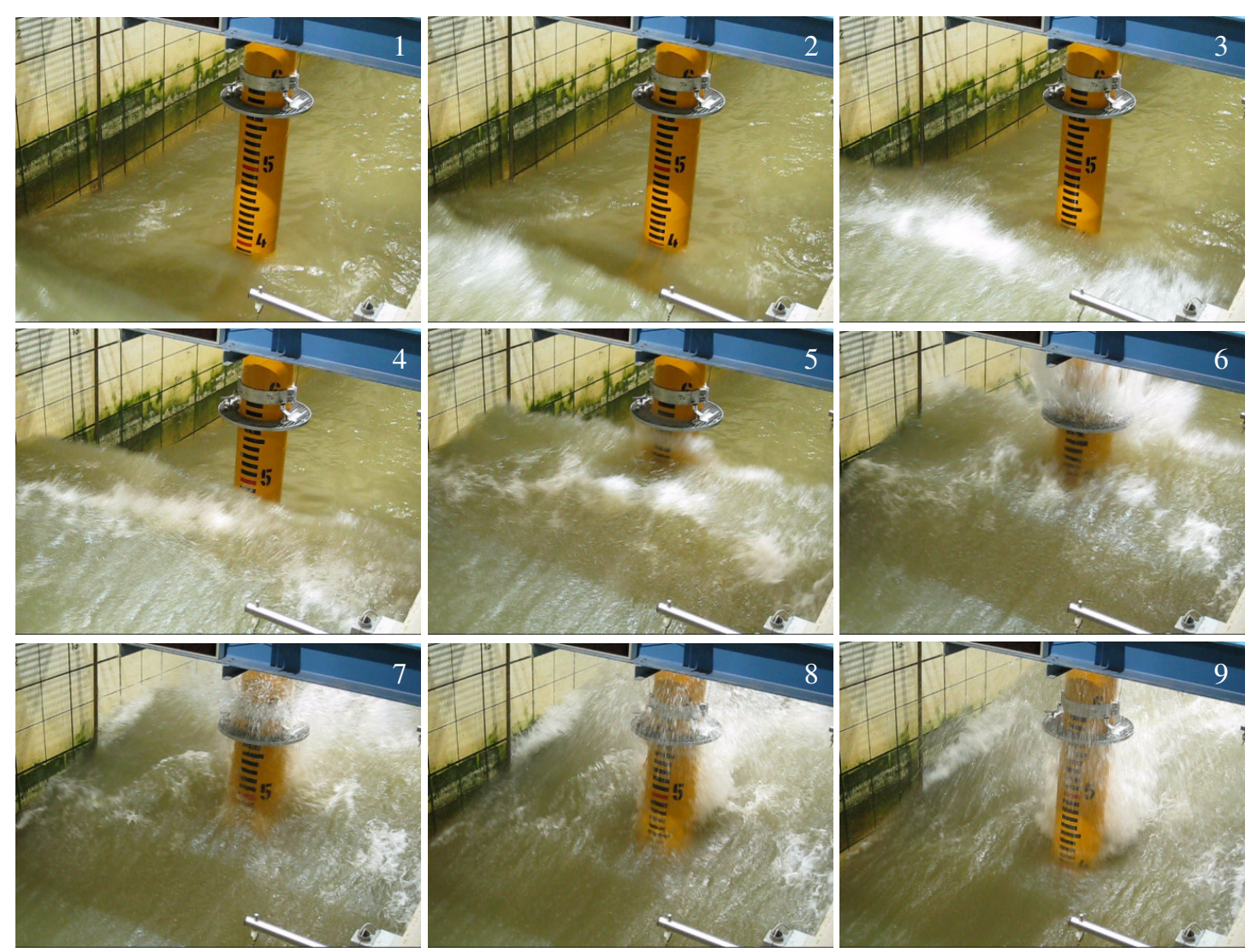

Figure 11. Pictures $(\Delta t=0.20 \mathrm{~s}$ ) of impacting irregular wave on grate platform (porosity $84 \%$ ) at level $+\mathbf{1 . 7 5}$. Maximum load $0.51 \mathrm{kN}$ for $h=3 \mathrm{~m}, H_{\mathrm{m} 0}=1.0 \mathrm{~m}$ and $T_{\mathrm{p}}=5.9 \mathrm{~s}$, all values in model scale. 


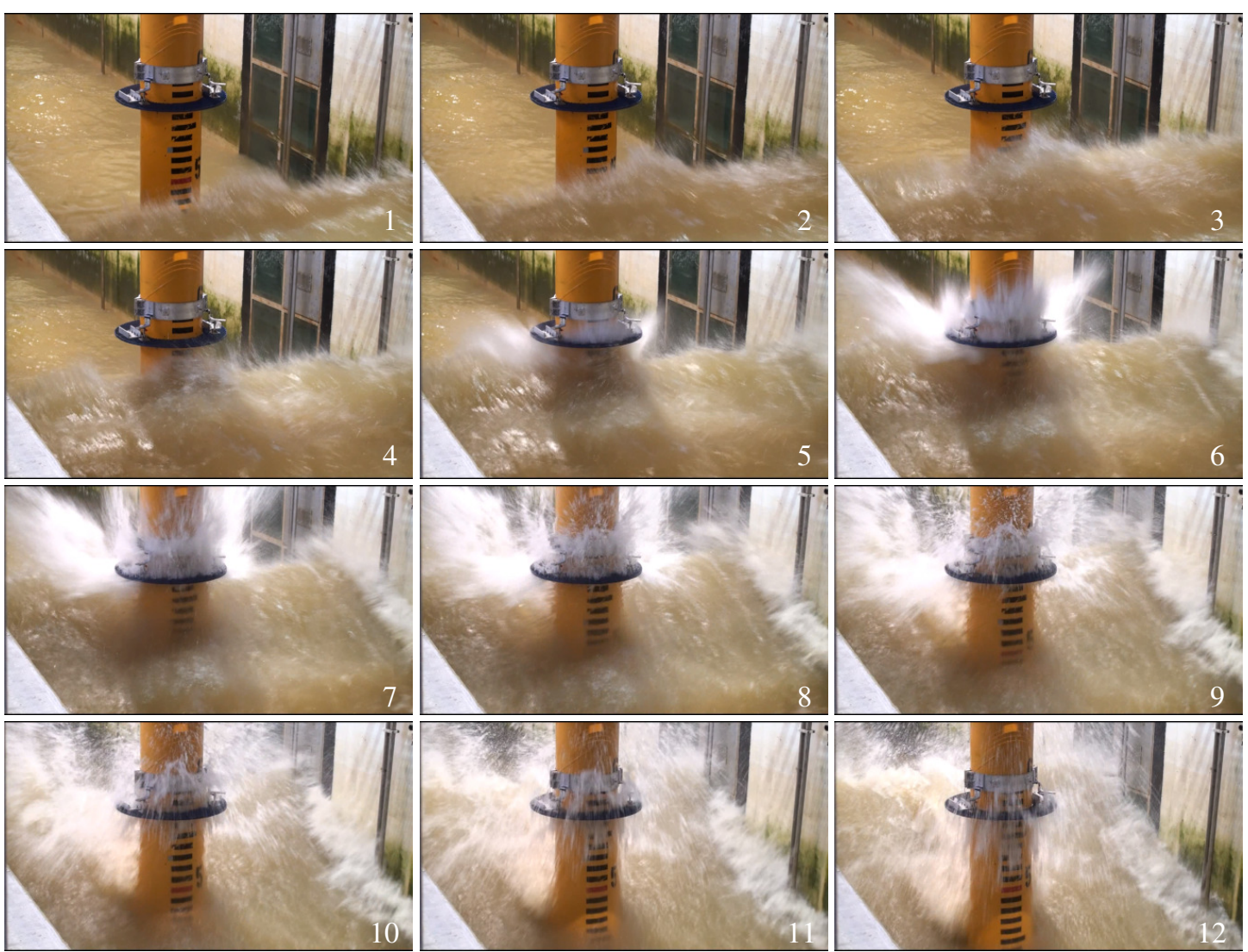

Figure 12. Pictures $(\Delta t=0.08 \mathrm{~s}$ ) of impacting irregular wave on grate platform (porosity $70 \%$ ) at level $+\mathbf{1 . 7 5}$. Maximum load $1.05 \mathrm{kN}$ for $h=3 \mathrm{~m}, H_{\mathrm{m} 0}=1.0 \mathrm{~m}$ and $T_{\mathrm{p}}=5.9 \mathrm{~s}$, all values in model scale.

By comparing Figs. 11-13 it is evident that the solid plate experiences significantly larger forces than the porous grates. The grate multiplication factors for the maximum vertical loads seems to be slightly larger than the solidity ( 1 - porosity), i.e. slightly larger than found for drag.

A summary of the obtained loads and the corresponding grate multiplication factors are given in Table 3.

\begin{tabular}{|c|c|c|}
\hline Porosity & Measured max. peak load & Grate multiplication factor \\
\hline $0 \%$ & $2.3 \mathrm{kN}$ & 1.00 \\
\hline $70 \%$ & $1.05 \mathrm{kN}$ & 0.46 \\
\hline $84 \%$ & $0.51 \mathrm{kN}$ & 0.22 \\
\hline
\end{tabular}

Fig. 14 shows the load history for the three impact examples shown in Figs. $11-13$. The loads consist of an impact load and some vibrations of the structure. Therefore, the maximum force is not the only parameter to describe the loads, but the time history is also very important. Moreover, the response of the prototype structure for such types of loads should be determined for design purposes in order to know if dynamic amplification or dampening occurs. Here it should be noted that the eigen frequency of the platform was $50-60 \mathrm{~Hz}$ in the model, which is expected to correlate quite well with prototype platforms of such types.

The duration of the impacts is less than $200 \mathrm{~ms}$ and highest for the closed plate platform. This means the impact impulse is significantly larger for the closed plate compared to the grates. 

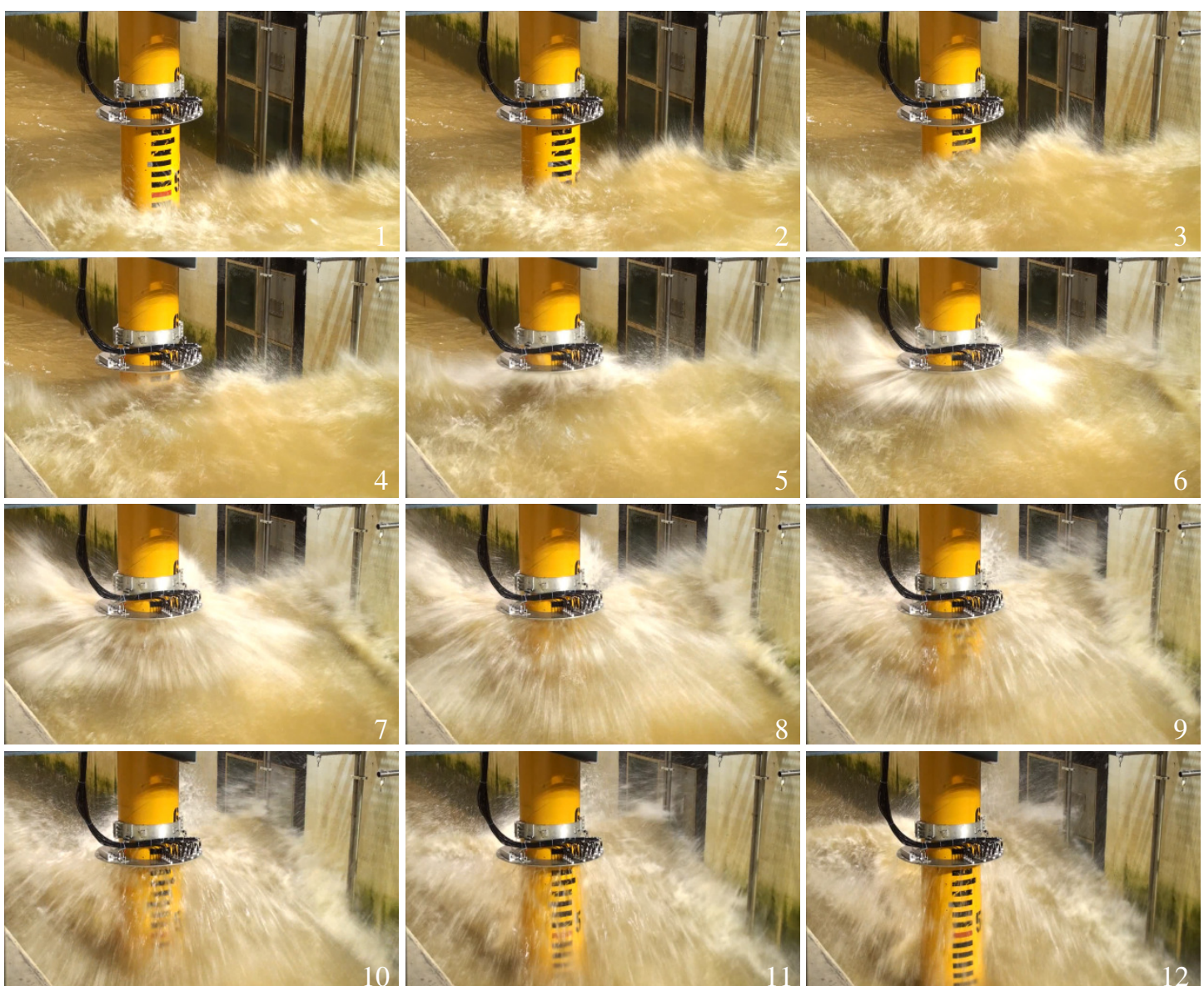

Figure 13. Pictures $(\Delta t=0.08 \mathrm{~s}$ ) of impacting irregular wave on solid platform (porosity $0 \%$ ) at level $+\mathbf{1 . 7 5}$. Maximum load $2.3 \mathrm{kN}$ for $h=3 \mathrm{~m}, H_{\mathrm{m} 0}=1.0 \mathrm{~m}$ and $T_{\mathrm{p}}=5.9 \mathrm{~s}$, all values in model scale.
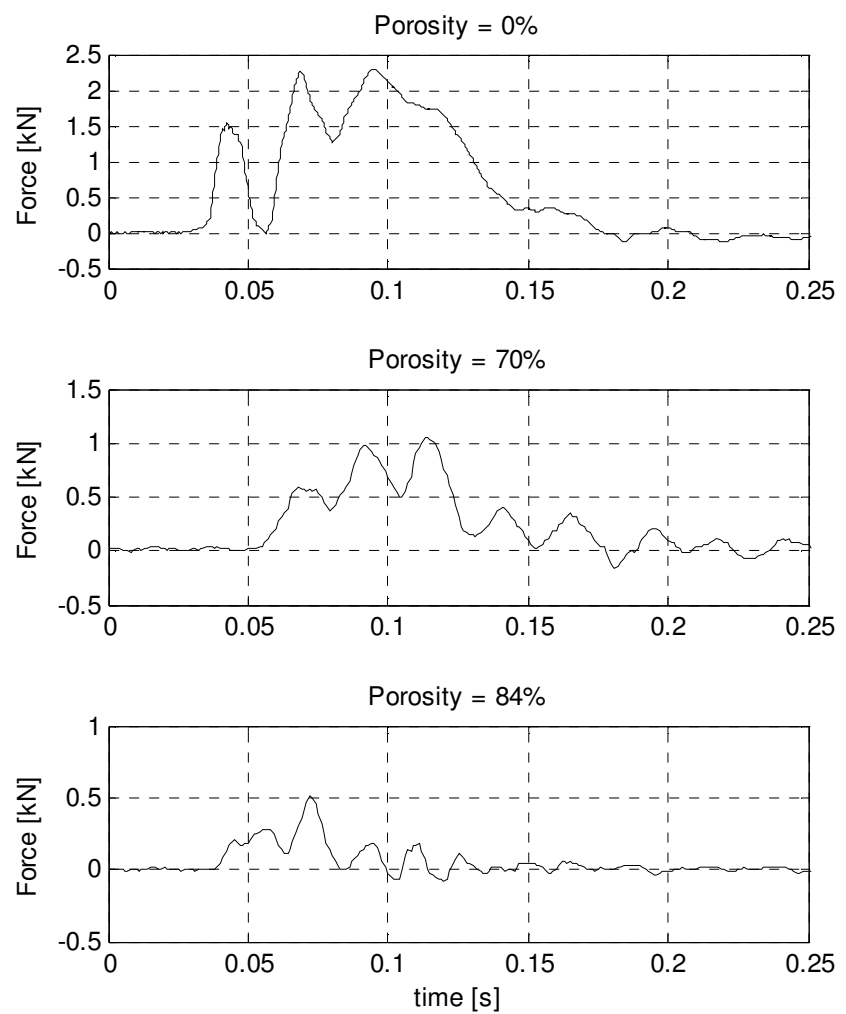

Figure 14. Total force time series of the three impacts shown in Fig. 11-13. 
Fig. 15 shows a comparison of peak loads for all impacts in the considered sea state. This is done for interrelated events (loads for same waves compared) and where the events are ranked after peak force for each platform type. In the latter situation we thus compare the highest peak loads on the three platform types, the second highest and so on.

It can be seen that if identical events are compared there is a very significant scatter on the grate multiplication factors. This shows that slamming loads are very sensitive to small differences in the wave kinematics for example caused by slightly different breaking.

When the loads are ranked after peak force the scatter almost disappears and it can be seen that the grate multiplication factor is approximately equal to the solidity of the grate $(1-\beta)$, but slightly larger for the highest event. This was found as a conservative limit in the drag tests for perpendicular attack.

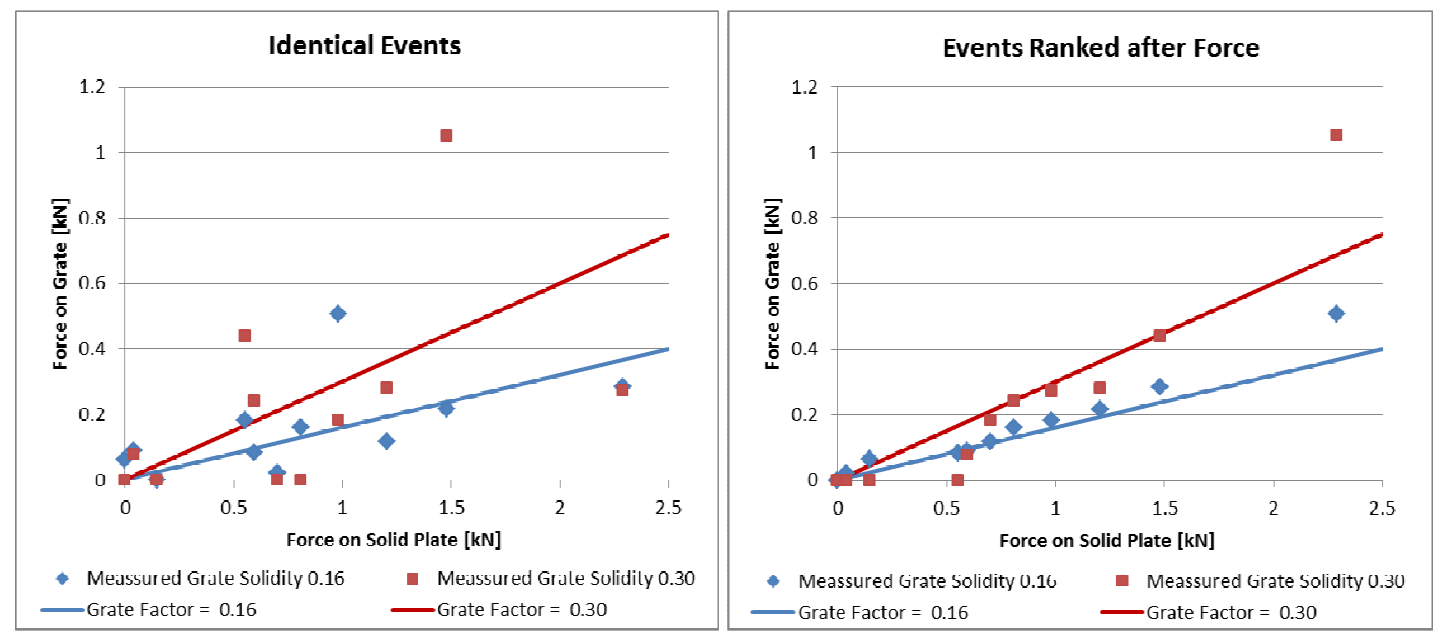

Figure 15. Peak loads for all events giving impact in the sea state.

It can also be seen that in this specific case $2 \%$ of the waves hit the platform. This shows the importance of the highest run-ups and the importance of the really extreme events. It also demonstrates that safety on platform loads cannot be included by the partial safety factor method as the phenomenon is extremely non-linear. Instead safety should be included by using a return period leading to the wanted safety level (for example $\mathrm{T}=10,000$ years). Combinations of sea state parameters corresponding to this return period should be established in order to calculate extreme design loads for example using the load model presented here. Even for the short lifetime of wind turbines, climate changes might also be very important to include.

\section{CONCLUSIONS}

A summary of recently performed model tests and associated design formulae for run-up and loads on closed plate platforms has been given. Moreover, results from two studies on loads on grates have been presented. The first study is drag load measurements from an impacting stationary small jet. The second study is based on large scale tests, where only preliminary results have been established at the moment. In the large scale tests were measured run-up heights as well as impact loads on different platform types.

Based on both studies it appears that peak loads on entrance platforms with grates can be calculated from the peak load on a closed plate platform multiplied by a grate multiplication factor. This grate multiplication factor was in both studied found to be approximately equal to the solidity of the grate (1 - porosity), but also slightly dependent on the detailed geometry of the grate.

However, the drag tests indicate that this is a conservative limit while based on a single large scale test condition it seems as a central or slightly unsafe estimate. Analysis of several of the large scale tests are needed to quantify if this is a general difference between the two studies. Because of this difference it must be concluded that the drag tests are very good to test different grates in order to find grates that meet the safety requirements and give small grate multiplication factors. The large scale tests give however a more realistic estimate of the actual flow and loading conditions and thus are the grate factors determined from these experiments expected to be more realistic for prototype conditions. 
An important conclusion is that both studies indicate that grates lead to a very significant reduction in the design loads compared to closed plate platforms. For very typical grate geometries the load is reduced by a factor 3-5 compared to solid plates and even higher if safety requirements allow grates with higher porosities. Investigations on force peak shapes are still ongoing.

Visual observations in small and large scale indicate that wave run-up and associated loads on platforms is very sensitive to the detailed wave kinematics. Wave breaking in irregular waves seems to be a key issue that at the moment is not well dealt with in the literature. To get maximum run-up a wave with steep front or a wave breaking directly on or slightly in front of the pile is needed. In the tests only very few of the waves have these characteristics (approx. 1-2\%). Also it should be noted that even though spilling breakers were expected from the Irribarren number, it was observed that few waves have a very steep front and are plunging or close to plunging.

\section{ACKNOWLEDGMENTS}

The large scale tests have been supported by European Community's Sixth Framework Programme through the grant to the budget of the Integrated Infrastructure Initiative HYDRALAB III within the Transnational Access Activities, Contract no. 022441.

\section{REFERENCES}

Annand, W. J. D. (1953). The Resistance to Air Flow of Wire Gauzes. Journal of the Royal Aeronautical Society, Vol. 57, p. 141-146.

De Vos, L., Frigaard, P. and De Rouck, J. 2007. Wave run-up on cylindrical cone shaped foundations for offshore wind turbines. Coastal Engineering 54 (1), 17-29, Elsevier.

Idelchik, I. E. (2003). Handbook of Hydraulic Resistance. CRC Begell House.

Lykke Andersen, T. and Frigaard, P. 2006a. Horns Rev II, 2-D Model Tests.Wave Run-Up on Pile. DCE Contract Report No. 3, Dept. of Civil Engineering, Aalborg University.

Lykke Andersen, T. and Brorsen, M. 2006. Horns Rev II, 2-D Model Tests. Impact Pressures on Horizontal and Cone Platforms. DCE Contract Report No. 4, Dept. of Civil Engineering, Aalborg University.

Lykke Andersen, T. and Brorsen, M. 2007. Horns Rev II, 2-D Model Tests. Impact Pressures on Horizontal and Cone Platforms from Irregular Waves DCE Contract Report No. 13, Dept. of Civil Engineering, Aalborg University.

Lykke Andersen, T., Rasmussen, M. R. and Frigaard, P. 2007b. Detailed Investigations of Load Coefficients on Grates. Influence of Air and Angle of Attack. DCE Contract Report No. 22, Aalborg University.

Lykke Andersen, T. and Rasmussen, M. 2008. Access Platforms for Offshore Wind Turbines Using Gratings. Proc. $8^{\text {th }}$ International Congress on Advances in Civil Engineering, Famagusta, North Cyprus, p. 379-386.

Lykke Andersen, T., Frigaard, P., Damsgaard, M.L. and De Vos, L. Wave Run-Up on Slender Piles in Design Conditions - Model Tests and Design Rules for Offshore Wind. Coastal Engineering, Elsevier (submitted)

Morgan, P. G. (1962). Flow through screens of low solidity. Journal of the Royal Aeronautical Society, Vol. 66, p. 54-56.

Nielsen, A.W., Mortensen, S.B., Jacobsen, V. and Damgaard Christensen, E. 2008. Numerical Modelling of Wave Run-Up on a Wind Turbine Foundation. Proc. Of the ASME $27^{\text {th }}$ Int. Conf. on Offshore and Arctic Engineering, Estoril, Portugal, p. 597-603.

Richards, P. J. \& Robinson, M. (1999). Wind Loads on Porous Structures. Journal of Wind Engineering and Industrial Aerodynamics 83, p. 455-465. 